\title{
Toxicity of Polybrominated Biphenyls (Firemaster BP-6) in Rodents
}

\author{
T. H. Corbett, A. R. Beaudoin, R. G. Cornell, \\ M. R. Anver, R. Schumacher, J. Endres, \\ AND M. SZWABOWSKA \\ The Research Service, U.S.V.A. Hospital; the Department of \\ Anatomy, and the Unit for Laboratory Animal Medicine, \\ University of Michigan Medical School, \\ Ann Arbor, Michigan 48104
}

Received March, 5. 1975

\begin{abstract}
Pregnant rodents were fed concentrations of a mixture of polybrominated biphenyls (Firemaster BP-6) during the pregnancy. The material appears to be weakly teratogenic, causing exencephaly and cleft palate in mice. Decreasing birth weight with increasing dosage of the material was seen in both mice and rats. Nonpregnant mice fed $1000 \mathrm{ppm}$ Firemaster BP-6 for 11 days had a marked increase in liver size and weight.
\end{abstract}

\section{INTRODUCTION}

For a period of not less than 1 year, a mixture of polybrominated biphenyls was mistakenly added to large amounts of livestock feed in Michigan. This commercial product has the brand name Firemaster BP-6, and is manufactured by the Michigan Chemical Company. It has an average bromine content of six bromine atoms per biphenyl molecule. The mixture consists mainly of penta-, hexa-, and heptabromobiphenyl, with lesser amounts of tetra-, and other brominated biphenyls (Report to Michigan Environmental Review Board, 1974). The material has not been analyzed for the presence of brominated dibenzofurans or other contaminants.

Cows which ingested the contaminated feed developed anorexia and decreased milk production initially, followed by weight loss and the appearance of hematomas. Abnormal growth of the hoofs and alopecia also occurred. Pregnant animals delivered 2 to 4 weeks late. Many calves were stillborn or died soon after birth. Necropsy reports of cows which succumbed to the PBB mixture mentioned liver changes, including fatty metamorphosis, large fat vacuoles replacing liver cells, and amyloidosis. One cow was reported to have hemorrhagic necrotic hepatitis. Acute, subacute, and chronic interstitial nephritis was reported, and absomasal ulcers were present in several animals. Numerous hematomas and abcesses were also reported (Jackson and Halbert, 1974).

Contamination of the livestock food resulted in the consumption of this chemical mixture by several million people through the ingestion of contaminated meat and animal products. The levels of consumption ranged from several thousand parts per million in meat of contaminated dairy cows to less than $1 \mathrm{ppm}$ in milk sold in supermarkets throughout the state. 
Although little is known about the toxicity of polybrominated biphenyls, numerous deleterious effects have been reported from a structurally similar group of chemicals, the polychlorinated biphenyls. PCBs are known to be embryolethal and cause reduction in birth weight in rats. Teratogenicity has been demonstrated in chickens, and carcinogenic activity has been reported in rats and mice. Enzyme induction, as well as injury to liver cells has been demonstrated. Immunosuppressive activity of PCBs is also well documented (Fishbein, 1974).

An outbreak of PCB poisoning, known as the Yusho Incident, occurred in Japan in 1968. At least 1,000 people were affected. A latency period of 5-6 months was reported before the onset of symptoms, which included chloracne, blindness, gastrointestinal symptoms with jaundice, edema, and abdominal pain. Newborn infants of poisoned mothers had skin discoloration. Decreased birth weight was noted. Gingival hypertrophy was noted in several cases. An in-depth study of four of the infants revealed that the frontal and occipital fontanelles were abnormally large, and the sagittal suture was abnormally wide. Their faces were swollen, and there was exophthalmia in three cases (Kuratsune et al., 1969).

The acute and long-term toxicity of polybrominated biphenyls in humans is unknown. Because of the widespread human exposure to Firemaster BP-6, we designed a project to study several parameters of toxicity of this material.

\section{MATERIALS AND METHODS}

Groups of female Swiss/ICR mice and Sprague-Dawley rats were ordered timed-pregnant (sperm day $=$ Day 0) from Spartan Laboratories, Hastings, Michigan. They were exposed to either 50,100 , or $1,000 \mathrm{ppm}$ Firemaster BP-6 in commercial rodent chow from Days 7-18 of the pregnancy for mice, and from Days 7-20 of the pregnancy for rats. In addition, one group of nonpregnant female mice was exposed to 1,000 ppm Firemaster BP-6 in the diet for 11 days. Control groups were fed uncontaminated feed of the same type. All animals were given food and water ad libitum.

All groups of pregnant animals were killed and examined 1 day prior to the expected day of delivery (Day 18 for mice, Day 20 for rats). The uteri were examined intact, noting the number of implantations and resorptions. The uteri were then incised, and the living and dead fetuses counted. Living fetuses were weighed. Half the fetuses from each litter were preserved in Bouin's fluid and later examined for anomalies by razor sectioning. The other half of each litter was preserved in $95 \%$ alcohol, cleared with $2 \%$ potassium hydroxide, and stained with Alizarin red-S for examination of the skeletal system.

Selected liver, fat, and fetal tissues from the $1,000 \mathrm{ppm}$ mouse groups were analyzed by gas chromatography for concentrations of polybrominated biphenyls. In addition, three human fat specimens, obtained at autopsy, were similarly analyzed. These individuals were males, ages 15, 46, and 52, who resided in southern lower Michigan.

Livers of nonpregnant control and 1,000 ppm mice were weighed, and the relative organ weight calculated for each animal. Samples of control and 1,000 ppm mouse livers were fixed in $10 \%$ buffered neutral formalin, sectioned at $6 \mu \mathrm{m}$, and stained with $\mathrm{H}$ and $\mathrm{E}$ for routine light microscopy. 
Liver microsomes were prepared from one control and one PBB-treated mouse essentially as described by van der Hoeven and Coon (1974), except that a pestle-type homogenizer was used. The concentration of cytochrome P-450 in the microsomal suspensions was determined from the reduced carbon monoxide difference spectrum (van der Hoeveh and Coon, 1974; Omura and Sato, 1964), and the protein concentration was determined by the method of Lowry et al. 1951 .

Polyacrylamide gel electrophoresis of the microsomal proteins in the presence of sodium dodecyl phosphate (SDS) (van der Hoeven and Coon, 1974) was performed in a slab gel apparatus using the discontinuous buffer system of Laemmli (1970) and a separating gel $(0.75 \mathrm{~mm}$ thick) containing $7.5 \%$ acrylamide. The microsomal suspensions were solubilized by treatment with SDS and betamercaptoethanol at 100 degrees. In this and similar systems, the migration of proteins is a function of their molecular weight (Weber and Osborn, 1969).

\section{RESULTS}

Noticeable effects of Firemaster BP-6 on rat pregnancy included a decrease in mean fetal weight with increasing dose of the polybrominated biphenyl mixture, and suggestion of late fetal mortality at the $1000 \mathrm{ppm}$ concentration. However, the mice exhibited not only the decreasing mean fetal weight with increasing dosage, but also exencephaly (Fig. 1) at both the 1000 and $100 \mathrm{ppm}$ dosages, and cleft palate and hydronephrosis at the $1000 \mathrm{ppm}$ (Table 1). Several animals in experimental groups of both rats and mice died of massive gastrointestinal hemorrhage prior to the scheduled necropsy time.

The statistical significance of the decreasing fetal weight with increasing dosage was tested. Separate analyses of variance were done for rats and mice. The design was hierarchical with animals nested within treatments and fetuses nested within rodents. Because of the unequal numbers of rodents per group, and fetuses per rodent, Satterthwaite's approximation was used in testing the hypothesis that the group means, including the control group mean, do not differ. For rats, an approximate $F$-statistic with 2 and $22{ }^{\circ} \mathrm{F}$ of 3.78 was obtained. For mice, the ${ }^{\circ} \mathrm{Fs}$ were 3 and 38 , and the approximate $F$-statistic was 3.58 . The first is significant at the $5 \%$ level, and the second at the $2.5 \%$ level. Thus, for both rats and mice, the groups differ significantly, and it is evident from the table that there is a dose relationship with fetal weight decreasing with increasing dosage.

The data on exencephaly in mice fetuses were analyzed by merging the three experimental groups into a single group for comparison with the control group. Even though all five cases were among mice exposed to Firemaster BP-6, the number of mice in the present study was not enough to assert that the exencephaly rate is higher in mice exposed to Firemaster BP-6 than among controls. However, when an outside control group of Spartan Laboratories Swiss mice (from Parke-Davis Laboratories, Ann Arbor, Michigan) is added to the control group, the corresponding chi-square statistic is 9.12 which is significant at the 0.005 level. Analysis of the incidence of cleft palate comparing the combined exposure groups and the combined control groups using the chi-square test with continuity correction revealed the difference to be significant $(p=0.05)$ based on a chi-square value of 4.47 . 


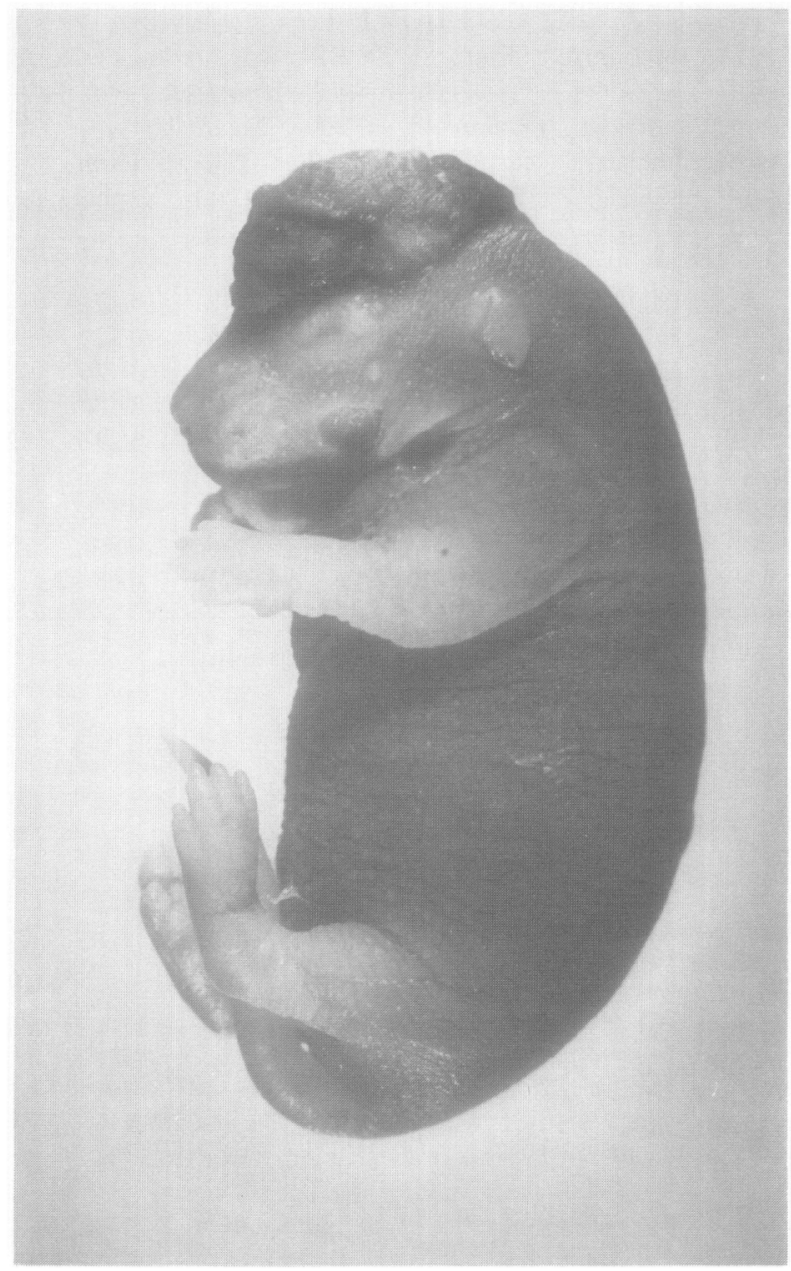

FIG. 1. Exencephaly in a mouse fetus (day 18). The mother was fed $100 \mathrm{ppm}$ polybrominated biphenyls (Firemaster BP-6) in the diet from Days 7-18 of the pregnancy.

There was a noticeable increase in liver weight over controls in the $1000 \mathrm{ppm}$ mice, and nmoles P-450/mg microsomal protein was increased, indicating that enzyme induction had occurred. The mean liver weights for eight control and eight experimental mice were 6.49 and $13.93 \%$ of total body weight, respectively. This difference was significant ( $p=0.02$ ) using the Wilcoxon Rank Sum Test.

The specific content of the microsomal cytochrome P-450 increased significantly from 2.0 for the control, to $3.7 \mathrm{nmole} / \mathrm{mg}$ protein for the PBB-treated mouse. This increase is comparable to induction caused by the administration of polycyclic hydrocarbons to mice (Nebert and Bausserman, 1970) and chlorinated biphenyls to rats (Alvares and Siekevitz, 1973).

The electrophoretic patterns of the microsomes from the two treatments are similar (Fig. 2). However, the microsomes from the PBR-treated mouse had a dramatically increased concentration of one band, or possibly two close bands, 
TABLE 1

Results of Feeding Firemaster BP-6 lo Prelinani Rudenis

\begin{tabular}{|c|c|c|c|c|c|c|c|}
\hline Concentration $\mathrm{HBB}$ & $\begin{array}{l}\text { Implan } \\
\text { tations }^{a}\end{array}$ & $\begin{array}{l}\text { Fetal death } \\
\text { early and } \\
\text { late }=\text { total }\end{array}$ & $\begin{array}{l}\text { Fetal } \\
\text { death } \\
(\%)\end{array}$ & $\begin{array}{c}\text { Mean } \\
\text { fetal } \\
\text { wt. (g) }\end{array}$ & $\begin{array}{c}\text { Exen- } \\
\text { cephaly }\end{array}$ & $\begin{array}{c}\text { Cleft } \\
\text { palate }\end{array}$ & $\begin{array}{c}\text { Hydro- } \\
\text { nephrosis }\end{array}$ \\
\hline \multicolumn{8}{|l|}{ Suiss/ICR Mict' } \\
\hline 0 (control) & $190(16)$ & $16+1=17$ & 8.9 & 1.40 & $0 / 173$ & $0 / 87$ & $0 / 87$ \\
\hline $50 \mathrm{ppm}$ & $131(9)$ & $5+2=7$ & 5.3 & 1.35 & $0 / 122$ & $1 / 61$ & $0 / 61$ \\
\hline $100 \mathrm{ppm}$ & $130(9)$ & $8+2=10$ & 7.7 & 1.36 & $3 / 121$ & $0 / 60$ & $0 / 60$ \\
\hline $1000 \mathrm{ppm}$ & $186(12)$ & $14+2=16$ & 8.6 & 1.20 & $2 / 174$ & $4 / 87$ & $2 / 87$ \\
\hline Parke-Davis control & & & & & $6 / 2975$ & 23/2975 & $128 / 2975$ \\
\hline \multicolumn{8}{|l|}{ Sprague-Dawley rats } \\
\hline 0 (control) & $140(12)$ & $12+0=12$ & 8.6 & 4.23 & $0 / 128$ & $0 / 64$ & $0 / 64$ \\
\hline $100 \mathrm{ppm}$ & $83(7)$ & $3+0=3$ & 3.6 & 3.96 & $0 / 80$ & $0 / 40$ & $0 / 40$ \\
\hline $1000 \mathrm{ppm}$ & $75(6)$ & $6+4=10$ & 13.3 & 3.73 & $0 / 65$ & $0 / 33$ & $0 / 33$ \\
\hline
\end{tabular}

${ }^{a}$ Numbers in parentheses indicate number of samples tested.

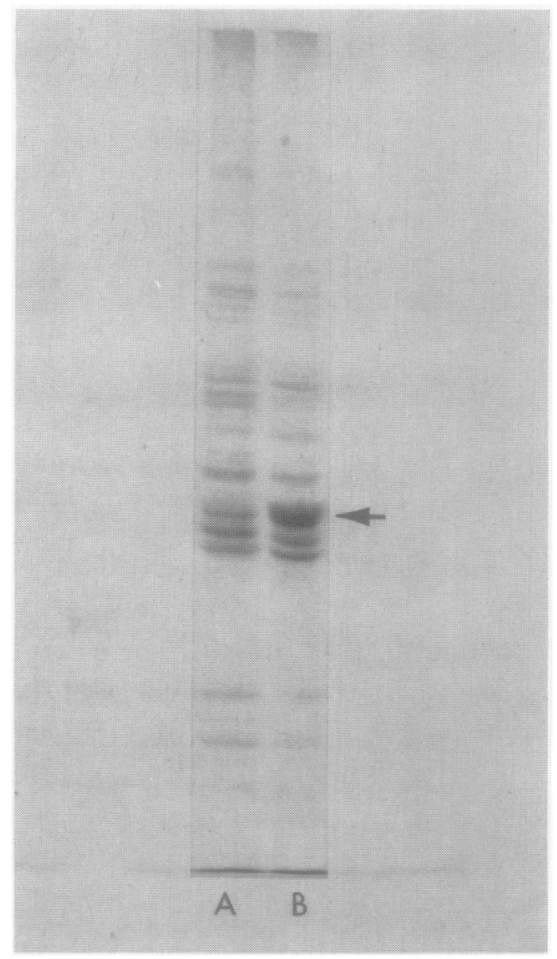

FIG. 2. SDS-Polyacrylamide gel electrophoresis of liver microsomes from the control and PBBtreated mice. Electrophoresis was performed as described in methods using $5 \mu \mathrm{g}$ of microsomal protein for each treatment: A, control; B. PBB-treated. The arrow indicates the position of the band(s) increased in concentration by PBB treatment. Migration was from top to bottom. 
TABLE 2

Tissue LeVels of PBB in Mice Fed 1000 ppm for 11 Days

\begin{tabular}{cccc}
\multicolumn{1}{c}{ Tissue $^{\prime \prime}$} & Mean (ppm) & Range (ppm) \\
\hline Control fetus (3) & 0.05 & $0.02-0.06$ \\
$1000 \mathrm{ppm}$ fetus (3) & 0.53 & $0.17-0.86$ \\
Control liver (1) & 0.04 & 0.04 \\
1000 ppm liver (7) & 2.51 & $1.52-3.57$ \\
$1000 \mathrm{ppm}$ fat $(4)$ & 39.52 & $16.4-57.6$ \\
\hline
\end{tabular}

"Numbers in parentheses indicate the number of samples tested.

with molecular weight about 55,000. Other experiments with mice (Nebert, Haugen, and Coon, 1975; Nebert, Haugen, and Coon, in preparation) have demonstrated that one of the two bands in this area is induced by the administration of beta-naphthoflavone and the other by pregnenolone-15-alpha-carbonitrile. Concomitant increases in the spectral concentration of P-450 and in enzyme activities associated with $\mathrm{P}-450$ were also observed.

Histological examination of the $1000 \mathrm{ppm}$ mouse livers revealed swelling of hepatocytes with focal areas of coagulative necrosis. Other areas of dark staining hepatocytes were noted.

Table 2 shows the concentrations of polybrominated biphenyls in tissues of mice fed $1000 \mathrm{ppm}$ Firemaster BP-6 from Days 7-18 of the pregnancy. Fetal and liver concentrations are reported in $\mathrm{ppm}$ in whole tissue.

The three human fat specimens all contained detectable levels of polybrominated biphenyls, all below $100 \mathrm{ppb}$.

\section{DISCUSSION}

The toxicity of polybrominated biphenyls in humans is unknown. The recent widespread contamination of foodstuffs in Michigan, and the demonstration of teratogenicity of Firemaster BP-6 in mice is cause for concern. Although polychlorinated biphenyls are not generally considered to be highly teratogenic, the chlorinated dibenzofuran contaminants found in these chemical mixtures are teratogenic. The presence of brominated dibenzofurans or other contaminants in Firemaster BP-6 must be considered.

Firemaster BP-6 appears to be a potent enzyme inducing agent. Although this condition can affect the metabolism or numerous other drugs and chemicals, the overall effect on the human population is unknown.

Although carcinogenicity of certain polychlorinated biphenyls has been reported in rodents, studies of the carcinogenicity of Firemaster BP-6 have not yet been performed.

The findings of this study and the known toxic effects of the structurally similar polychlorinated biphenyls suggest that monitoring the exposed human population is advisable. Although the more highly exposed farm families have demonstrated little symptomatology to the present time, teratogenicity, mutagenicity, and carcinogenicity are parameters that deserve intense investigation, now and in the future. 


\section{ACKNOWLEDGMENTS}

The authors are indebted to Dr. David A. Haugen, Department of Biological Chemistry. Medical School, The University of Michigan, for his collaboration in this project.

This project was supported by VA Research Funds, by NIH grants HD 08130 and HD 00400, and by a private donation from $\mathrm{Mr}$. and Mrs. Lawrence Yax.

\section{REFERENCES}

Alvares, A. P., and Siekevitz, P. (1973). Gel Electrophoresis of partially purified cytochromes P-450 from variously-treated rats. Biochem. Biophys. Res. Commun. 54, 923-929.

Fishbein, L. (1974). Toxicity of chlorinated biphenyls. Ann. Rev. Pharmacol. 14, 139-156.

Jackson, T. F., Halbert, F. L. (1974). A toxic syndrome associated with the feeding of polybrominated biphenyl-contaminated protein concentrate to dairy cattle. J. A. V. M. A. 165, 437-439.

Kuratsune, M. et al. 1969. Yusho, a poisoning caused by rice oil contaminated with chlorobiphenyls. Fukuoka Acta Med. 60, 513-532.

Laemmli, U. K. (1970). Cleavage of structural proteins during the assembly of the head of the bacteriophage T-4. Nature (London) 227, 680-685.

Lowry, O. H., Rosebrough. N. J., Farr. A. L., and Randall, R. J. (1951). J. Biol. Chem. 193, 262-275.

Nebert, D. W.. and Bausserman. L. L. (1970). Genetic differences in the extent of aryl hydrocarbon hydroxylase induction in mouse fetal cell cultures. J. Biol. Chem. 245, 6373-6382.

Nebert, D. W., Haugen, D. A., and Coon. M. J. (1975). Abstracts. Sixth Intl. Cong. Pharmacol. (in press).

Nebert, D. W., Haugen, D. A., and Coon, M. J., manuscript in preparation.

Omura, T., and Sato, R. (1964). The carbon monoxide-binding pigment of liver microsomes. J. Biol. Chem. 239, 2370-2378.

Report to Michigan Environmental Review Board from Michigan Chemical Company, September 23. 1974.

van der Hoeven, T. A., and Coon, M. J. (1974). Preparation and properties of a partially purified cytochrome P-450 and reduced nicotinamide adenine dinucleotide phosphate-cytochrome P-450 reductase from rabbit liver microsumes. J. Biol. Chem. 249, 6302-6310.

Weber, K.. and Osborn, M. (1969). The reliability of molecular weight determinations by dodecyl sulfate-polyacrylamide gel electrophoresis. J. Biol. Chem 244, 4406-4412. 